\title{
Influence of Five Different Root Canal Sealers on Root Fracture Susceptibility
}

\author{
${ }^{1}$ Emre Bayram, ${ }^{2}$ Hüda Melike Bayram
}

\begin{abstract}
Aim: The purpose of the study was to compare the fracture resistance of roots filled with one of the following five root canal sealers: AH Plus, EndoRez, RealSeal, MTA Fillapex, and AcroSeal. The null hypothesis was that the type of root canal sealer would not influence the fracture resistance of root-filled teeth.
\end{abstract}

Methods: Sixty-five maxillary central incisors were sectioned $1 \mathrm{~mm}$ below the cementoenamel junction (CEJ) to obtain roots $14 \mathrm{~mm}$ in length. Roots were subjected to chemomechanical preparation using the rotary instruments of the Profile system. The obturation of root canals was performed with the following filling materials $(n=12)$ : group I: AH Plus and gutta-percha (GP), group II: EndoRez and GP, group III: RealSeal and GP, group IV: MTA Fillapex and GP, group V: AcroSeal and GP, group VI: roots were instrumented but not filled (control; $n=5$ ). After the appropriate setting time, each root was embedded in acrylic resin. The specimens were then subjected to fracture resistance testing using an Instron testing machine at $1 \mathrm{~mm} / \mathrm{min}$.

Results: The Mann-Whitney test indicated no significant differences $(p>0.05)$ among groups I $(379.10 \pm 57.64 \mathrm{~N})$, II $(374.32 \pm$ $101.61 \mathrm{~N})$, III $(309.06 \pm 87.10 \mathrm{~N})$, IV $(305.99 \pm 76.67 \mathrm{~N})$, $\mathrm{V}(362.91 \pm 91.23 \mathrm{~N})$ and VI $(213.711 \pm 51.85 \mathrm{~N})$. Groups I to V were all significantly better than the control, but no difference between them.

Conclusion: All of the root canal sealers used in this study increased the fracture resistance of instrumented root canals.

Keywords: Fracture resistance, Reinforce, Root canal sealers.

How to cite this article: Bayram E, Bayram HM. Influence of Five Different Root Canal Sealers on Root Fracture Susceptibility. J Contemp Dent 2015;5(3):165-167.

Source of support: Nil

\section{Conflict of interest: None}

\section{INTRODUCTION}

Tooth fracture has been described as a major problem in dentistry; it is the third most common cause of tooth loss after dental caries and periodontal disease. ${ }^{1,2}$

\footnotetext{
${ }^{1,2}$ Assistant Professor

1,2Department of Endodontics, Gaziosmanpasa University Tokat, Turkey

Corresponding Author: Emre Bayram, Assistant Professor Department of Endodontics, Gaziosmanpasa University Tokat, Turkey, Phone: +905058598284, e-mail: bayremre@ yahoo.com
}

It is commonly believed that endodontically treated teeth are weaker and more prone to fracture than vital teeth. ${ }^{3}$ Several factors are known to be associated with root fractures in endodontically treated teeth, including excessive loss of tooth structure because of caries or trauma, dehydration of dentin, access cavity preparation, instrumentation and irrigation of the root canal, excessive pressure during root obturation, and preparation of intraradicular post space. ${ }^{4,5}$ Therefore, one of the objectives of root canal obturation is to reinforce the root canal and increase root fracture resistance. It is thought that adhesion and mechanical interlocking between the root canal filling material and radicular dentin reduce the risk of fracture and strengthen the remaining tooth structure. ${ }^{6}$

The purpose of this study was to compare the fracture resistance of roots filled with gutta-percha (GP) and sealed with one of the following five root canal sealers: epoxy resin-based AH Plus, resin-based EndoRez, resinbased RealSeal, MTA-based MTA Fillapex, and calcium hydroxide-based AcroSeal. The null hypothesis was that the type of root canal sealer would not influence the fracture resistance of root-filled teeth.

\section{METHODS}

Sixty-five freshly extracted, intact, human maxillary central incisors with single straight root canals were selected for this study. Teeth were stored in distilled water until use. To ensure that incisor roots with standardized dimensions were used, the buccolingual and mesiodistal dimensions of the root canals were measured using a digital calliper. Preoperative radiographs were taken in the mesiodistal and buccolingual directions to evaluate the presence of a single canal, resorptions, or calcifications. The crowns were removed at the cementoenamel junction (CEJ) to standardize the root length $(14 \mathrm{~mm})$ with a high-speed bur under water cooling. The working length was determined by subtracting $1 \mathrm{~mm}$ from the length of an inserted \#15 K-file (Dentsply Maillefer, Ballaigues, Switzerland) with its tip visualized at the apical foramen. All of the root canals were instrumented to an apical size of F3 (30) with the rotary ProTaper system (Dentsply Maillefer) using the crown-down technique. Along with this 
instrumentation, $5.25 \% \mathrm{NaOCl}$ irrigation was applied between each file. Following instrumentation, all canals were irrigated with $5 \mathrm{ml}$ of $17 \%$ EDTA solution followed by $5 \mathrm{ml}$ of $\mathrm{NaOCl}$ to remove the smear layer. The canals were finally rinsed with $5 \mathrm{ml}$ of distilled water, dried using paper points, and divided into five experimental groups of 12 teeth each according to the obturating materials and the root canal sealers used. Root canals of all teeth were obturated using the lateral condensation technique. The groups were classified as follows: group I, AH Plus (Dentsply DeTrey, Konstanz, Germany) sealer and GP; group II, EndoRez (Ultradent, South Jordan, UT, USA) sealer and GP; group III, RealSeal (SybronEndo, Orange, CA) sealer and GP; group IV, MTA Fillapex (Angelus Industria de Produtos Odontologicos S/A, Londrina, Brazil) sealer and GP; group V, AcroSeal (Septodont, Saint-Maur-des-Fosses, France) sealer and GP; group VI, roots were instrumented but not filled (control).

Mesiodistal and buccolingual radiographs were taken to verify complete filling. After root filling, the coronal $2 \mathrm{~mm}$ of the filling materials was removed, and the spaces were filled with a temporary filling material (Cavit; $3 \mathrm{M}$ ESPE, Seefeld, Germany). The teeth were stored at $37^{\circ} \mathrm{C}$ with $100 \%$ humidity for 7 days to allow the sealers to set.

Acrylic resin blocks were prepared $10 \mathrm{~mm}$ in height and $20 \mathrm{~mm}$ in diameter. All of the roots were mounted vertically in self-cure acrylic resin (Meliodent; Bayer Dental, Leverkuser, Germany). The apical root ends were embedded vertically in $5 \mathrm{~mm}$ of the acrylic resin, exposin $9 \mathrm{~mm}$ of the coronal portion of each root. A universal testing machine (Instron Corp, Canton, MA, USA) was used for the strength test. The acrylic blocks were placed on the lower plate of the machine. The upper plate consisted of a spherical steel tip with a diameter of $2 \mathrm{~mm}$. The tip was centered over the canal orifice, and a slowly increasing vertical force was exerted $(1 \mathrm{~mm} / \mathrm{min})$ until fracture occurred. The maximum force required to fracture each specimen was recorded in Newtons $(\mathrm{N})$ and the results were compared. Statistical analysis was performed using Kruskal-Wallis and Mann-Whitney tests.

\section{RESULTS}

Table 1 shows the mechanical testing results. According to the Kruskal-Wallis tests, there were statistically significant differences among the I to VI groups $(\mathrm{p}<0.05)$. The Mann-Whitney U-test revealed no significant differences among groups I to $\mathrm{V}(\mathrm{p}>0.05)$. Groups I to $\mathrm{V}$ were all significantly better than the control, but no difference between them.
Table 1: Minimum, maximum, and mean values of fracture strength (in Newtons) for both experimental and control groups

\begin{tabular}{|c|c|c|c|c|c|}
\hline Groups & $N$ & $\begin{array}{l}\text { Mean } \\
\text { value }\end{array}$ & Min. & Max. & $S D$ \\
\hline I (AH Plus) & 12 & 379.10 & 297.41 & 451.80 & 57.64 \\
\hline II (EndoRez) & 12 & 374.32 & 149.63 & 532.89 & 101.61 \\
\hline III (MTA Fillapex) & 12 & 309.06 & 148.45 & 374.04 & 87.10 \\
\hline IV (RealSeal) & 12 & 305.99 & 208.46 & 492.52 & 76.67 \\
\hline V (AcroSeal) & 12 & 362.91 & 233.23 & 588.86 & 91.23 \\
\hline IV (Control) & 5 & 213.71 & 157.69 & 290.84 & 51.85 \\
\hline
\end{tabular}

\section{DISCUSSION}

Standardization of the samples is an important factor in mechanical testing. Variations in the dimensions of the roots, extraction time, and storage conditions may affect the results. ${ }^{7}$ According to Versluis et $\mathrm{l}^{8}$ root canal preparations that resulted in a round cross-section led to more uniform stress distributions within a root during filling, thereby reducing fracture susceptibility.

In this study, we used standardized instrumentation, irrigation and obturation procedures. To standardize the apical canal diameter of the enlarged root canal, all roots were prepared to ProTaper size F3, corresponding to an apical size 30. A standard irrigation regimen, using EDTA and sodium hypochlorite, was used to remove the smear layer because this combination has been shown to enhance bonding of the materials tested to the dentinal surface of the root. ${ }^{9}$

Lertchirakarn et $\mathrm{al}^{10}$ evaluated the vertical fracture resistance with different root filling materials and sealers. Their study demonstrated that the sealer type did not significantly influence fracture load with the same core material; the core material was more important in terms of strengthening or reinforcing the root filling. ${ }^{10}$ For this reason, was used as the core material to assess the impact of root canal sealers in the current study.

For fracture strength measurement, in many studies, loading force was applied in a vertical direction because a vertical force applied parallel to the long axis of a tooth produces a more uniform stress distribution. ${ }^{11,12}$ Therefore, in the current study, a single load to fracture was applied in the vertical direction with a cross-head speed of $1 \mathrm{~mm}$ minute $^{-1}$ using a universal testing machine.

In this study, filling of the root canals with AH Plus sealer did not significantly strengthen the roots compared with other sealers; in fact, no differences were detected among root canal sealers $(p>0.05)$. These results corroborate previous findings. 13,14

The epoxy resin-based sealers penetrate microirregularities better due to their creep capacity and high polymerization time. ${ }^{15}$

Materials that adhere to the root canal dentin surface will reinforce an endodontically treated tooth 
structure. ${ }^{6,16,17}$ All of the experimental groups I to V showed significantly superior fracture resistance compared with the control group. This result is consistent with those of Karapinar et $\mathrm{al}^{18}$ and Sagsen et $\mathrm{al}^{14}$ and verifies the reinforcing effect of the filling materials.

Hammad et al compared vertical forces at fracture of teeth obturated with Endorez, RealSeal and Guttaflow; they found that forces at fracture were significantly higher in the Realseal and EndoRez groups than Guttaflow. ${ }^{19} \mathrm{We}$ also found no significant differences between EndoRez and RealSeal, but the Endorez fracture load values were higher than those of RealSeal. This difference between studies may be caused by RealSeal being used with.

In other studies, MTA as a root canal filling material strengthened the root against fracture. ${ }^{20,21}$ In the current study, the MTA-based root canal sealer MTA Fillapex showed significantly higher fracture resistance compared with the negative control group, although it was not significantly different from the other root canal sealers tested. This may be due to the presence of resins in MTA Fillapex.

\section{CONCLUSION}

Within the limitations of this study, we concluded that the obturation of roots with resin-based materials increased the resistance of root-canal-filled teeth to vertical root fracture. Use of adhesive resin-based sealers will prolong the clinical usage of such teeth.

\section{REFERENCES}

1. Ellis SG, McCord JF, Burke FJ. Predisposing and contributing factors for complete and incomplete tooth fractures. Dent Update 1999;26(4):150-152.

2. Braly BV, Maxwell EH. Potential for tooth fracture in restorative dentistry. J Prosthet Dent 1981;45(4):411-414.

3. Schwartz RS, Robbins JW. Post placement and restoration of endodontically treated teeth: a literature review. J Endod 2004;30(5):289-301.

4. Tang $\mathrm{W}, \mathrm{Wu} \mathrm{Y}$, Smales RJ. Identifying and reducing risks for potential fractures in endodontically treated teeth. J Endod 2010;36(4):609-617.

5. Sedgley $\mathrm{CM}$, Messer $\mathrm{HH}$. Are endodontically treated teeth more brittle? J Endod 1992;18(7):332-335.

6. Schafer E, Zandbiglari T, Schafer J. Influence of resin-based adhesive root canal fillings on the resistance to fracture of endodontically treated roots: an in vitro preliminary study. Oral
Surg Oral Med Oral Pathol Oral Radiol Endod 2007;103(2): 274-279.

7. Cobankara FK, Ungor M, Belli S. The effect of two different root canal sealers and smear layer on resistance to root fracture. J Endod 2002;28(8):606-609.

8. Versluis A, Messer HH, Pintado MR. Changes in compaction stress distributions in roots resulting from canal preparation. Int Endod J 2006;39(12):931-939.

9. Kokkas AB, Boutsioukis A, Vassiliadis LP, Stavrianos CK. The influence of the smear layer on dentinal tubule penetration depth by three different root canal sealers: an in vitro study. J Endod 2004;30(2):100-102.

10. Lertchirakarn V, Poonkaew A, Messer H. Fracture resistance of roots filled with gutta-percha or RealSeal(R). Int Endod J 2011;44(11):1005-1010.

11. Apicella MJ, Loushine RJ, West LA, Runyan DA. A comparison of root fracture resistance using two root canal sealers. Int Endod J 1999;32(5):376-380.

12. Ghoneim AG, Lutfy RA, Sabet NE, Fayyad DM. Resistance to fracture of roots obturated with novel canal-filling systems. J Endod 2011;37(11):1590-1592.

13. Bhat SS, Hegde SK, Rao A, Shaji Mohammed AK. Evaluation of resistance of teeth subjected to fracture after endodontic treatment using different root canal sealers: an in vitro study. J Indian Soc Pedod Prev Dent 2012;30(4):305-309.

14. Sagsen B, Ustun Y, Pala K, Demirbuga S. Resistance to fracture of roots filled with different sealers. Dent Mater J 2012;31(4): 528-532.

15. Sousa-Neto MD, Marchesan MA, Pecora JD, Junior AB, SilvaSousa YT, Saquy PC. Effect of Er:YAG laser on adhesion of root canal sealers. J Endod 2002;28(3):185-187.

16. Ungor M, Onay EO, Orucoglu H. Push-out bond strengths: the Epiphany-Resilon endodontic obturation system compared with different pairings of Epiphany, Resilon, AH Plus and gutta-percha. Int Endod J 2006;39(8):643-647.

17. Gesi A, Raffaelli O, Goracci C, Pashley DH, Tay FR, Ferrari M. Interfacial strength of Resilon and gutta-percha to intraradicular dentin. J Endod 2005;31(11):809-813.

18. Karapinar Kazandag M, Sunay H, Tanalp J, Bayirli G. Fracture resistance of roots using different canal filling systems. Int Endod J 2009;42(8):705-710.

19. Hammad M, Qualtrough A, Silikas N. Effect of new obturating materials on vertical root fracture resistance of endodontically treated teeth. J Endod 2007;33(6):732-736.

20. Andreasen JO, Munksgaard EC, Bakland LK. Comparison of fracture resistance in root canals of immature sheep teeth after filling with calcium hydroxide or MTA. Dent Traumatol 2006;22(3):154-156.

21. Cauwels RG, Pieters IY, Martens LC, Verbeeck RM. Fracture resistance and reinforcement of immature roots with guttapercha, mineral trioxide aggregate and calcium phosphate bone cement: a standardized in vitro model. Dent Traumatol 2010;26(2):137-142. 